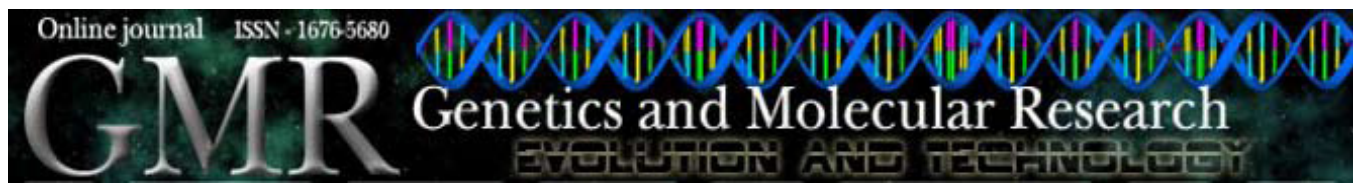

\title{
Endothelial nitric oxide synthase gene polymorphisms and essential hypertension in Han Chinese
}

H.G. Wang ${ }^{1 *}$, J.L. Wang ${ }^{2,3 *}$, P. Chang ${ }^{1}$, F.L. Cao ${ }^{4}$, X.C. Liu ${ }^{1}$, Y.B. Ma ${ }^{1}$, G.X. Zhai ${ }^{5}$ and H.Q. Gao ${ }^{6}$

${ }^{1}$ Department of Pharmacy, Qilu Hospital, Shandong University, Jinan, China ${ }^{2}$ Department of Emergency, Qilu Hospital, Shandong University, Jinan, China

${ }^{3}$ Key Laboratory of Cardiovascular Remodeling and Function Research Affiliated to Ministry of Education of the P.R. China and Ministry of Health of the P.R. China, Shandong University, Jinan, China

${ }^{4}$ School Infirmary, Shandong University, Jinan, China

${ }^{5}$ Department of Pharmaceutics, School of Pharmacy, Shandong University, Jinan, China

${ }^{6}$ Department of Gerontology, Qilu Hospital, Shandong University, Jinan, China

*These authors contributed equally to this study.

Corresponding author: H.Q. Gao

E-mail: sdwfbf@163.com

Genet. Mol. Res. 9 (3): 1896-1907 (2010)

Received May 28, 2010

Accepted July 12, 2010

Published September 21, 2010

DOI 10.4238/vol9-3gmr946

ABSTRACT. We examined the effect of polymorphisms in the endothelial nitric oxide synthase gene on the risk for essential hypertension in a Han Chinese population through a meta-analysis of data from 15 studies. Associations between increased risk for essential hypertension and $4 \mathrm{~b} / \mathrm{a}$ were obtained in a dominant model and allele contrast $\left(\mathrm{aa}+\mathrm{ab} v s\right.$ bb: odds ratio $(\mathrm{OR})_{\mathrm{FE}}=1.26,95 \%$ confidence interval $(\mathrm{CI})=1.10-1.44$; a $v$ s b allele: $\mathrm{OR}_{\mathrm{FE}}=1.23$, 95\%CI: 1.09 1.40). Four studies with sample sizes over 500 produced similar results. No evidence of publication bias was found. Also, no significant heterogeneity was observed among these studies. When we examined 
the G894T polymorphism, we found a marginally significant association for allele contrast and the recessive model when all the eligible studies were pooled together. However, there was no evidence for a significant association after the exclusion of two studies deviating from HardyWeinberg equilibrium in the control group. Heterogeneity among studies was observed. Results of cumulative and recursive cumulative meta-analysis indicated that more studies are needed to objectively determine the effects of these two polymorphisms.

Key words: Endothelial nitric oxide synthase; Polymorphism; Meta-analysis; Essential hypertension

\section{INTRODUCTION}

Hypertension is thought to be a multifactorial disorder causing severe damage to human health. It is estimated that over $95 \%$ of adult hypertension is of the essential hypertension (EH) type (Dosh, 2002). The pathogenesis of EH is determined by both genetic and environmental factors, in which genetic contributes up to 30 to $50 \%$ (Newhouse et al., 2005). Many genes involved in blood pressure regulation have been screened and recognized as candidates for hypertension, such as endothelial nitric oxide synthase (eNOS) gene. This gene encodes the protein that synthesizes nitric oxide (NO) constitutively via a reaction involving the conversion of L-arginine to L-citrulline (Mayer and Hemmens, 1997; Miyamoto et al., 1998). Data from mechanistic studies suggest that NO plays a crucial role in the maintenance of normal endothelial function, blood pressure and cardiovascular homeostasis (Schmidt and Walter, 1994; Nejatizadeh et al., 2008). An association between altered NO metabolism and hypertension has been found both in animal and clinical studies (Huang et al., 1995; Forte et al., 1997). Because endothelial NO availability is regulated at the level of synthesis, the eNOS gene is hypothesized to be a candidate for $\mathrm{EH}$ and draws considerable attention.

The eNOS gene is located on chromosome 7q35-36 and consists of 26 exons (Miyahara et al., 1994). Several polymorphisms have been identified and much attention has been focused on the following variants: G894T, 4b/a, T-786C, and A922G (Thomas et al., 2001; Thaha et al., 2008). The G894T polymorphism, a $\mathrm{G}$ to $\mathrm{T}$ conversion at nucleotide position 894 in exon 7, results in a replacement of glutamate by aspartate at codon 298 . This variant is not located in any functional consensus sequence, but computer analysis has revealed that the G894T mutation results in a conformational change in the eNOS protein from helix to tight turn (Miyamoto et al., 1998). The 4b/a polymorphism is a variable number of tandem repeat polymorphism located in intron 4 of the eNOS gene and has been reported to have a strong association with plasma NO levels. The mean plasma NO level of the subjects who are homozygous for the a allele is nearly $20 \%$ lower than in the subjects with the b allele (Tsukada et al., 1998).

Although functional experiments support the involvement of eNOS polymorphisms in the pathogenesis of $\mathrm{EH}$, results of association studies have remained inconsistent. It may be a result of the few participants in each study. Also, data from different populations with various genetic backgrounds may lead to conflicting findings. Two earlier studies that performed 
meta-analyses to evaluate the effect of eNOS variants on the risk of hypertension yielded different conclusions (Zintzaras et al., 2006; Pereira et al., 2007).

In this study, we performed a meta-analysis of data from 15 studies carried out in China. Our main aim was to estimate the effect of polymorphisms in eNOS on EH susceptibility in Han Chinese and to provide more information on hypertension candidate gene study.

\section{MATERIAL AND METHODS}

\section{Selection of studies}

All studies published in the Chinese Biomedicine Database, the China National Knowledge Infrastructure platform, Medline and Embase before May 20, 2010, were searched using the following search terms: "hypertension", "blood pressure", "nitric oxide synthase", "eNOS", "NOS3", "gene", "polymorphism", "China", and "Chinese", without any restriction on language. The potentially associated publications were evaluated by checking their titles and abstracts, and then, eligible studies were searched for a closer examination. All references cited in the articles were also scanned to identify relevant publications.

Studies that determined the distribution of eNOS polymorphisms among EH cases and healthy/normotensive controls in Han Chinese were eligible for inclusion in the metaanalysis. Case subjects were diagnosed according to criteria of systolic blood pressure $\geq 140$ $\mathrm{mmHg}$ or diastolic blood pressure $\geq 90 \mathrm{mmHg}$. Case reports, review articles and studies were excluded for any of the following criteria: 1) no control population; 2) duplication of earlier publication; 3) no extractable data for cases or controls, and 4) containing secondary forms of hypertension in the case group. For studies with overlapping cases/controls, the most recent ones with the largest number of participants were included in the meta-analysis.

\section{Data extraction}

Two of the authors extracted the data from each article independently. From each study, the following items were considered: first author's name, year of publication, ethnicity, numbers of participants, and clinical characteristics. Discrepancies were resolved until consensus was achieved.

\section{Statistical analysis}

The associations of eNOS polymorphisms with EH risk for allele contrast, dominant and recessive models were examined and evaluated by odds ratios (ORs) with the corresponding $95 \%$ confidence intervals (CIs) in the meta-analysis.

The heterogeneity among the included studies was assessed using Cochran's $Q$-statistic (Zintzaras and Ioannidis, 2005). $\mathrm{P}<0.10$ indicated heterogeneity across studies; the between-study variance $I^{2}$ metric $\left[I^{2}=(Q-\right.$ d.f. $\left.) / Q\right]$, which is independent of the number of studies, was then used to quantify the degree of heterogeneity. The $I^{2}$ metric takes values between 0 and $100 \%$, with values $>30 \%$ suggesting heterogeneity (Higgins and Thompson, 2002). The pooled OR was estimated using the fixed-effects model (Mantel-Haenszel) when homogeneity was observed. Alternatively, the random-effects model (DerSimonian Laird) was selected (Zintzaras et al., 2006). 
Potential publication bias was evaluated using Egger's regression test and the BeggMazumdar test (Macaskill et al., 2001). In analogy with $Q$-statistic, $\mathrm{P}<0.10$ rather than for $\mathrm{P}$ $<0.05$ was considered to be statistically significant in the publication bias tests. Otherwise, a $P$ value of less than 0.05 was chosen. Pearson's $\chi^{2}$ test was used to evaluate Hardy-Weinberg equilibrium (HWE) in the control group for all studies. If there were studies with controls not in HWE, sensitivity analysis was carried out to examine the effect of excluding specific studies (Trikalinos et al., 2006). In addition, a further sensitivity analysis was carried out by including only large studies (e.g., total sample size $>500$ subjects). The influence of an individual study was evaluated by estimating the pooled ORs in the absence of each study (Tobias, 1999). In order to evaluate the trend in OR over time, cumulative and recursive meta-analysis was performed for each polymorphism (Zintzaras and Lau, 2008). Analyses were performed with the Stata software (version 10.0; Stata Corporation, College Station, TX, USA), using two-sided P values.

\section{RESULTS}

\section{Literature search and meta-analysis databases}

A total of 137 potentially relevant articles on the Chinese population were searched and screened for retrieval. Among them, 92 were excluded for not being closely relevant to the association between eNOS polymorphisms and hypertension. In the remaining 45 articles, 14 were later excluded for overlapping data published by the same investigators and 1 excluded for not indicating EH in the case group. Thirty articles were on the study of the association of eNOS polymorphisms and hypertension in Chinese, of which 14 were in Han Chinese, encompassing 19 studies.

Among the 19 studies, 8 dealt with G894T (Liu and Ha, 2002; Tan et al., 2003; Li DB et al., 2004; Liang et al., 2006; Ma et al., 2006; Zhao et al., 2006; Li DJ et al., 2009; Niu et al., 2009), 7 with 4b/a (Huang et al., 2002; Li et al., 2003; Zhao X et al., 2005; Zhao Q et al., 2006; Yuan et al., 2007; Niu et al., 2009; Wu and Huang, 2009) and 4 with T-786C (Li et al., 2006; Ma et al., 2006; Zhao et al., 2006; Niu et al., 2009). One article provided data for males and females, respectively (Ma et al., 2006). Nine articles stated that cases and controls were age- and gender-matched (Huang et al., 2002; Liu and Ha, 2002; Tan et al., 2003; Zhao X et al., 2005; Li et al., 2004, 2006; Liang et al., 2006; Zhao Q et al., 2006; Yuan et al., 2007). Only one article mentioned blindness to the case-control status (Niu et al., 2009). In two studies on G894T (Tan et al., 2003; Niu et al., 2009), one on 4b/a (Yuan et al., 2007) and two on T-786C (Ma et al., 2006; Niu et al., 2009), the distribution of the genotypes in the control group was not in HWE $(\mathrm{P}<0.05)$, indicating genotyping errors and/or selection bias in the recruitment of controls (Zintzaras and Lau, 2008). All the studies were published between 2002 and 2009. The gene polymorphisms were used for meta-analysis with the exception of T-786C, because of the limited number of eligible studies and a high ratio of studies with controls not in HWE. The descriptive characteristics of all the included studies are provided in Table 1. In the eligible studies, there were 2882 cases and 2242 controls for G894T, and 3091 cases and 2622 controls for $4 \mathrm{~b} / \mathrm{a}$. The average $\mathrm{T}$ and the a allele frequency in normotensive Han Chinese was 12 and $9.1 \%$, respectively. Detailed information regarding genotype distribution and allele frequency for cases and controls is available in Table 2. 
H.G. Wang et al.

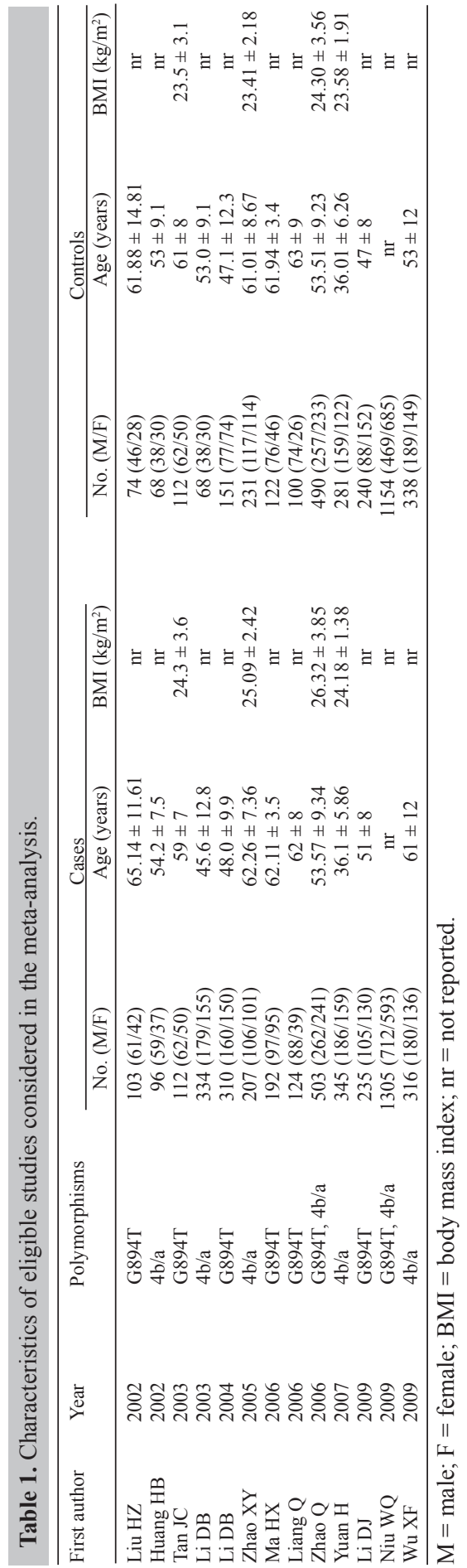


eNOS polymorphisms and essential hypertension in Han Chinese

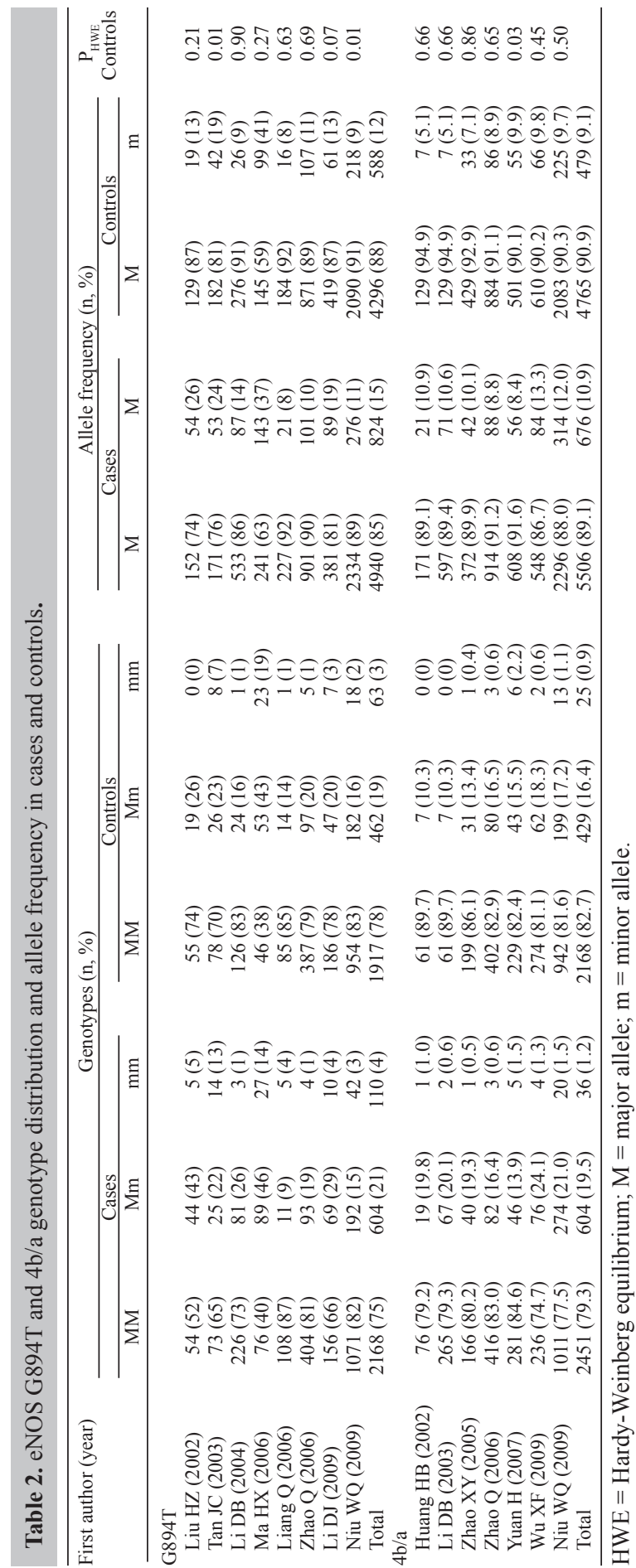




\section{Association between G894T polymorphisms and EH}

Table 3 and Figure 1 show the results for the association between the G894T polymorphism and EH. Overall, allele contrast and the recessive model produced marginally significant association when all the eligible studies were pooled together (allele contrast: $\mathrm{OR}_{\mathrm{RE}}=1.25,95 \% \mathrm{CI}=1.01-1.55$; recessive model: $\mathrm{OR}_{\mathrm{FE}}=1.46,95 \% \mathrm{CI}=1.06-2.00$ ), while negative results were obtained in the dominant model $\left(\mathrm{OR}_{\mathrm{RE}}=1.26,95 \% \mathrm{CI}=0.98-1.61\right)$.

\begin{tabular}{|c|c|c|c|c|c|c|}
\hline Population & Genetic model & Studies & $I^{2}(\%)$ & $\mathrm{P}(Q$-test $)$ & $\mathrm{OR}_{\mathrm{FE}}(95 \% \mathrm{CI})$ & $\mathrm{OR}_{\mathrm{RE}}(95 \% \mathrm{CI})$ \\
\hline \multirow[t]{3}{*}{ G894T All } & Dominant model & 8 & $62.2 \%$ & 0.01 & $1.17(1.02-1.33)$ & $1.26(0.98-1.61)$ \\
\hline & Allele contrast & 8 & $62.2 \%$ & 0.01 & $1.18(1.05-1.33)$ & $1.25(1.01-1.55)$ \\
\hline & Recessive model & 8 & $33.5 \%$ & 0.16 & $1.46(1.06-2.00)$ & $1.44(0.91-2.27)$ \\
\hline \multirow[t]{3}{*}{ All in HWE } & Dominant model & 6 & $70.3 \%$ & 0.01 & $1.26(1.05-1.52)$ & $1.34(0.93-1.92)$ \\
\hline & Allele contrast & 6 & $72.3 \%$ & $<0.01$ & $1.20(1.03-1.41)$ & $1.30(0.94-1.79)$ \\
\hline & Recessive model & 6 & $16.1 \%$ & 0.31 & $1.08(0.69-1.67)$ & $1.09(0.62-1.90)$ \\
\hline \multirow[t]{3}{*}{ 4b/a All } & Dominant model & 7 & $40.4 \%$ & 0.12 & $1.26(1.10-1.44)$ & $1.27(1.04-1.56)$ \\
\hline & Allele contrast & 7 & $43.8 \%$ & 0.10 & $1.23(1.09-1.40)$ & $1.24(1.02-1.51)$ \\
\hline & Recessive model & 7 & $0.0 \%$ & 0.95 & $1.22(0.73-2.02)$ & $1.21(0.72-2.02)$ \\
\hline \multirow[t]{3}{*}{ All in HWE } & Dominant model & 6 & $23.6 \%$ & 0.26 & $1.32(1.14-1.52)$ & $1.33(1.10-1.61)$ \\
\hline & Allele contrast & 6 & $24.6 \%$ & 0.25 & $1.29(1.13-1.47)$ & $1.31(1.10-1.56)$ \\
\hline & Recessive model & 6 & $0.0 \%$ & 0.99 & $1.38(0.78-2.43)$ & $1.37(0.78-2.42)$ \\
\hline \multirow[t]{3}{*}{$>500$} & Dominant model & 4 & $43.8 \%$ & 0.15 & $1.19(1.03-1.38)$ & $1.16(0.94-1.43)$ \\
\hline & Allele contrast & 4 & $48.5 \%$ & 0.12 & $1.17(1.03-1.34)$ & $1.14(0.93-1.39)$ \\
\hline & Recessive model & 4 & $0.0 \%$ & 0.69 & $1.20(0.71-2.05)$ & $1.20(0.70-2.05)$ \\
\hline \multirow[t]{3}{*}{$>500$ in HWE } & Dominant model & 3 & $23.8 \%$ & 0.27 & $1.24(1.07-1.45)$ & $1.24(1.03-1.49)$ \\
\hline & Allele contrast & 3 & $23.8 \%$ & 0.27 & $1.23(1.06-1.41)$ & $1.22(1.03-1.45)$ \\
\hline & Recessive model & 3 & $0.0 \%$ & 0.99 & $1.38(0.76-2.52)$ & $1.38(0.75-2.52)$ \\
\hline
\end{tabular}

\begin{tabular}{|c|c|c|}
\hline Study ID (1st author) & OR $(95 \% \mathrm{CI})$ & $\%$ Weight \\
\hline Liu HZ (2002) & $2.41(1.36,4.28)$ & 8.49 \\
\hline Tan JC (2003) & $1.34(0.85,2.12)$ & 10.98 \\
\hline Li DB (2004) & $1.73(1.09,2.75)$ & 10.84 \\
\hline Ma HX (2006) & $0.87(0.63,1.21)$ & 14.48 \\
\hline Liang Q (2006) & $1.06(0.54,2.10)$ & 6.80 \\
\hline Zhao Q (2006) & $0.91(0.68,1.22)$ & 15.77 \\
\hline Li DJ (2009) & $1.60(1.13,2.29)$ & 13.72 \\
\hline Niu WQ (2009) & $1.13(0.94,1.37)$ & 18.91 \\
\hline Overall $(1-$ squared $=62.2 \%, P=0.010)$ & $1.25(1.01,1.55)$ & 100.00 \\
\hline NOTE: Weights are from random effects analysis & & \\
\hline 0.234 & & \\
\hline
\end{tabular}

Figure 1. Result of published studies of association between G894T polymorphism and hypertension in Han Chinese with the corresponding confidence interval at $95 \%(95 \% \mathrm{CI})$ for the allele contrast. Pooled odds ratios $(\mathrm{OR})$ are shown under a random-effects model. 
No significant publication bias was detected by formal statistics (Begg's test, $\mathrm{P}=0.27$; Egger's test, $\mathrm{P}=0.24)$. Important heterogeneity among these studies was observed in the dominant model and allele contrast (dominant model: $P_{Q \text {-statistic }}=0.01, I^{2}=62.2 \%$; allele contrast: $P_{Q \text {-statistic }}$ $=0.01, I^{2}=62.2 \%$ ). Nonetheless, no significant results were found in sensitivity analysis after exclusion of two studies deviating from $\mathrm{HWE}$ in the control group (allele contrast: $\mathrm{OR}_{\mathrm{RE}}=$ $1.30,95 \% \mathrm{CI}=0.94-1.79$; dominant model: $\mathrm{OR}_{\mathrm{RE}}=1.34,95 \% \mathrm{CI}=0.93-1.92$; recessive model: $\left.\mathrm{OR}_{\mathrm{FE}}=1.08,95 \% \mathrm{CI}=0.69-1.67\right)$. As only two studies had sample sizes greater than 500 , we did not carry out a further sensitivity analysis by sample sizes. The removal of any one study did not result in a movement of the point estimate outside the $95 \%$ CIs. The results suggest that no single study exhibited excessive study influence. Cumulative meta-analysis for allele contrast showed a declining trend in the estimated risk effect (Figure 2). The results obtained for recursive cumulative meta-analysis were not stable, and therefore, the existing evidence was not sufficient enough to claim or deny an association between G894T and EH in Han Chinese.

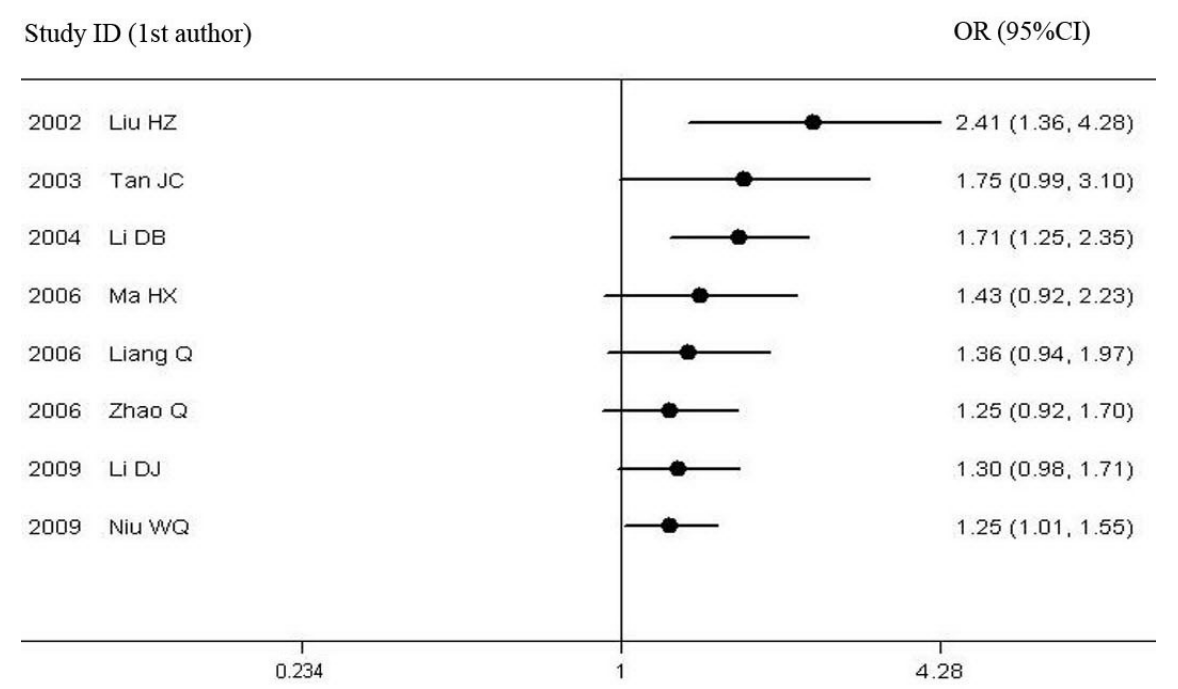

Figure 2. Cumulative meta-analysis for G894T polymorphism in the random-effects pooled odds ratio (OR) with the corresponding confidence interval at $95 \%(95 \% \mathrm{CI})$.

\section{Relationship between $4 \mathrm{~b} / \mathrm{a}$ polymorphism and $\mathrm{EH}$}

For the 4b/a polymorphism, significant association between the variant and an increased risk of $\mathrm{EH}$ was derived for allele contrast and the dominant model (allele contrast: $\mathrm{OR}_{\mathrm{FE}}=1.23,95 \% \mathrm{CI}=1.09-1.40$; dominant model: $\mathrm{OR}_{\mathrm{FE}}=1.26,95 \% \mathrm{CI}=1.10-1.44$; Figure 3 ). The heterogeneity between studies was not significant (allele contrast: $P_{Q \text {-statistic }}=0.10, I^{2}$ $=43.8 \%$; dominant model: $\left.P_{Q \text {-statistic }}=0.12, I^{2}=40.1 \%\right)$. The allele contrast indicated no significant publication bias (Begg's test, $\mathrm{P}=0.23$; Egger's test, $\mathrm{P}=0.42$ ). Sensitivity analysis revealed that the pattern of the results did not significantly change after exclusion of one study deviating from HWE in the control group (Table 3). A further sensitivity analysis including studies with sample sizes greater than 500 also produced positive results (allele contrast: $\mathrm{OR}_{\mathrm{FE}}$ $=1.17,95 \% \mathrm{CI}=1.03-1.34$; dominant model: $\mathrm{OR}_{\mathrm{FE}}=1.19,95 \% \mathrm{CI}=1.03-1.38$; Table 3$)$. There 
was no movement of the point estimate outside the $95 \%$ CIs after removal of any one study, indicating that no single study exhibited excessive study influence. Cumulative meta-analysis for allele contrast showed a declining trend in the estimated risk effect during 2002 and 2006, and then changed in the vicinity of 1.20 during 2006 and 2009 (Figure 4). The relative change in the fixed-effects ORs was lower than 1.00 until 2007 and then became 1.08 in 2009, indicating that more studies are needed to provide sufficient evidence.

\begin{tabular}{|c|c|c|}
\hline Study ID (1st author) & OR $(95 \% \mathrm{CI})$ & $\%$ Weight \\
\hline Huang HB (2002) & $-2.26(0.93,5.49)$ & 1.64 \\
\hline Li DB (2003) & $2.19(0.99,4.87)$ & 2.33 \\
\hline Zhao XY (2005) & $1.47(0.91,2.36)$ & 6.29 \\
\hline Zhao Q (2006) & $0.99(0.72,1.35)$ & 17.89 \\
\hline Yuan H (2007) & $0.84(0.57,1.24)$ & 12.30 \\
\hline Wu XF (2009) & $1.42(1.01,2.00)$ & 12.41 \\
\hline Niu WQ (2009) & $1.27(1.06,1.52)$ & 47.14 \\
\hline Overall (I-squared $=43.8 \%, P=0.099$ ) & $1.23(1.09,1.40)$ & 100.00 \\
\hline 0.182 & 49 & \\
\hline
\end{tabular}

Figure 3. Result of published studies of association between $4 \mathrm{~b} / \mathrm{a}$ polymorphism and hypertension in Han Chinese with the corresponding confidence interval at $95 \%(95 \% \mathrm{CI})$ for the allele contrast. Pooled odds ratios (OR) are shown under a fixed-effects model.

\begin{tabular}{llll} 
Study ID (1st author) & OR $(95 \% \mathrm{CI})$ \\
2002 Huang HB & $2.26(0.93,5.49)$ \\
2003 Li DB & $2.22(1.23,4.03)$ \\
2005 Zhao XY & & $1.76(1.22,2.54)$ \\
2007 Yhao Q & & $1.27(1.00,1.61)$ \\
2009 WuXF & & $1.14(0.93,1.39)$ \\
\hline
\end{tabular}

Figure 4. Cumulative meta-analysis for G894T polymorphism in the fixed-effects pooled odds ratios (OR) with the corresponding confidence interval at $95 \%(95 \% \mathrm{CI})$. 


\section{DISCUSSION}

In the present meta-analysis, the relationship between the two widely studied eNOS polymorphisms, G894T and 4b/a, and the risk of hypertension was examined. This study aimed to provide more information on hypertension candidate gene study, based on the hypothesis that genetic effects vary across different ethnicities. China is a united multiracial nation with the largest population in the world. We only selected the relatively homogeneous Han Chinese in our study to enhance statistical power and reduce genetic heterogeneity (Niu et al., 2009). By searching for articles from electronic databases in Chinese and English, this analysis comprised 11,037 participants, providing the most comprehensive evaluation on the association between eNOS variants and hypertension in Han Chinese so far.

In the analyses, the dominant model and sensitivity analysis failed to show significant association between G894T variant and EH in Han Chinese. Also, a fluctuating result of the relative change in the random-effects ORs was obtained in the recursive cumulative meta-analysis. Because the quality of studies with deviation from HWE is suspected to be poor (Trikalinos et al., 2006), we believe that the available data did not support the significant association between G894T polymorphisms and EH in Han Chinese. The results in our study on G894T were different from that carried out in 2007 (Pereira et al., 2007), a previous metaanalysis providing data on a similar population, i.e., East Asians. In that study, Pereira et al. (2007) reported significant results in East Asians in 2007 (15 studies included, 9 in Chinese). That could be the result of selective publication of positive studies, a common phenomenon in the entire field of biomedical research, especially in non-English speaking countries (Tang, 2005). At the same time, some studies in local journals in Chinese were not included in that meta-analysis, and then, there might have been a language bias.

Homozygosity for the T allele of the eNOS gene is rare in the Asian population. A low genotyping error rate or undetected population stratification would have a greater influence on the OR compared with studies in non-Asians (Casas et al., 2004). In our metaanalysis, there were only two studies with sample sizes more than 500, which might have contributed to the unstable results of G894T studies. As a result, studies with large sample sizes and high quality are needed.

The results of pooled analysis of $4 \mathrm{~b} / \mathrm{a}$ polymorphism and EH were significant. In addition, there was no evidence supporting the existence of publication bias or heterogeneity. Six studies in HWE and four studies with sample sizes more than 500 produced similar results. Therefore, there may be an association between increased risk of EH and $4 \mathrm{~b} / \mathrm{a}$. Given the intronic location of the $4 \mathrm{~b} / \mathrm{a}$ polymorphism, it is possible that the variant is in linkage disequilibrium with other functional variants in regulatory regions of the eNOS gene (Casas et al., 2006).

Taking certain limitations into account, the results of our meta-analysis should be treated with caution. First, the heterogeneity across studies was found in G894T polymorphism analyses, where the results could be misleading to some extent; second, we did not estimate the influence of potential confounders because of data limitation; third, gene-gene and gene-environment interactions were not tested in the present study, due to the lack of information from the original studies.

To conclude, the current meta-analysis indicates that $4 \mathrm{~b} / \mathrm{a}$ polymorphism in the eNOS gene is associated with an increased risk of EH in the Han Chinese population. Our results 
provide supplemental information to previous meta-analyses and knowledge regarding eNOS variants and hypertension. In order to further demonstrate the association of eNOS gene with hypertension, haplotypic approaches will provide more powerful and robust evidence regarding such association.

\section{REFERENCES}

Casas JP, Bautista LE, Humphries SE and Hingorani AD (2004). Endothelial nitric oxide synthase genotype and ischemic heart disease: meta-analysis of 26 studies involving 23028 subjects. Circulation 109: 1359-1365.

Casas JP, Cavalleri GL, Bautista LE, Smeeth L, et al. (2006). Endothelial nitric oxide synthase gene polymorphisms and cardiovascular disease: a HuGE review. Am. J. Epidemiol. 164: 921-935.

Dosh SA (2002). The treatment of adults with essential hypertension. J. Fam. Pract. 51: 74-80.

Forte P, Copland M, Smith LM, Milne E, et al. (1997). Basal nitric oxide synthesis in essential hypertension. Lancet 349: 837-842.

Higgins JP and Thompson SG (2002). Quantifying heterogeneity in a meta-analysis. Stat. Med. 21: 1539-1558.

Huang HB, Lin LX and Chen MQ (2002). Association of polymorphism of endothelial nitric oxide synthase gene with essential hypertension and type 2 diabetes mellitus. Chin. J. Endocrinol. Metab. 18: 16-19.

Huang PL, Huang Z, Mashimo H, Bloch KD, et al. (1995). Hypertension in mice lacking the gene for endothelial nitric oxide synthase. Nature 377: 239-242.

Li DB, Hua Q, Pi L, Zou HQ, et al. (2003). Association of polymorphism of endothelial nitric oxide synthase gene with essential hypertension. Chin. J. Hypertens. 11: 552-554.

Li DB, Hua Q and Pi L (2004). Association of G894T polymorphism of endothelial nitric oxide synthase gene and essential hypertension. Chin. J. Hypertens. 12: 326-330.

Li DB, Hua Q and Pi L (2006). The relationship of T786C polymorphism of endothelial nitric oxide synthase gene to essential hypertension. J. Cap. Univ. Med. Sci. 27: 226-229.

Li DJ, Wu WF, Xu L, Jiang XB, et al. (2009). Effect of G894T mutation in the endothelial nitric oxide synthase gene and abnormality of waist-to-hip ratio on essential hypertension. Chin. Gen. Pract. 12: 1173-1175, 1178.

Liang Q, Yang XY, Yang G and Cui JH (2006). Association of angiotensinogen and endothelial nitric oxide synthase gene polymorphism with essential hypertension. J. Youjiang Med. Col. Nationalities 28: 341-343.

Liu HZ and Ha DW (2002). Relationship between $894 \mathrm{G} \rightarrow \mathrm{T}$ polymorphism of endothelial nitric oxide synthase gene and essential hypertension. J. Chin. Circ. 17: 42-44.

Ma HX, Xie ZX, Niu YH, Li ZY, et al. (2006). Single nucleotide polymorphisms in NOS3 A-922G, T-786C and G894T: a correlation study of the distribution of their allelic combinations with hypertension in Chinese Han population. $\mathrm{Yi}$. Chuan 28: 3-10.

Macaskill P, Walter SD and Irwig L (2001). A comparison of methods to detect publication bias in meta-analysis. Stat. Med. 20: 641-654.

Mayer B and Hemmens B (1997). Biosynthesis and action of nitric oxide in mammalian cells. Trends Biochem. Sci. 22: 477-481.

Miyahara K, Kawamoto T, Sase K, Yui Y, et al. (1994). Cloning and structural characterization of the human endothelial nitric-oxide-synthase gene. Eur. J. Biochem. 223: 719-726.

Miyamoto Y, Saito Y, Kajiyama N, Yoshimura M, et al. (1998). Endothelial nitric oxide synthase gene is positively associated with essential hypertension. Hypertension 32: 3-8.

Nejatizadeh A, Kumar R, Stobdan T, Goyal AK, et al. (2008). Endothelial nitric oxide synthase gene haplotypes and circulating nitric oxide levels significantly associate with risk of essential hypertension. Free Radic. Biol. Med. 44: 1912-1918.

Newhouse SJ, Wallace C, Dobson R, Mein C, et al. (2005). Haplotypes of the WNK1 gene associate with blood pressure variation in a severely hypertensive population from the British genetics of hypertension study. Hum. Mol. Genet. 14: 1805-1814.

Niu WQ, Qi Y, Zhang LT, Qi YX, et al. (2009). Endothelial nitric oxide synthase genetic variation and essential hypertension risk in Han Chinese: the Fangshan study. J. Hum. Hypertens. 23: 136-139.

Pereira TV, Rudnicki M, Cheung BM, Baum L, et al. (2007). Three endothelial nitric oxide (NOS3) gene polymorphisms in hypertensive and normotensive individuals: meta-analysis of 53 studies reveals evidence of publication bias. $J$. Hypertens. 25: 1763-1774.

Schmidt HH and Walter U (1994). NO at work. Cell 78: 919-925. 
Tan JC, Zhu ZM, Zhu SJ, Yu CQ, et al. (2003). The GNB3 and eNOS gene polymorphisms in patients with essential hypertension. Chin. J. Cardiol. 31: 16-19.

Tang JL (2005). Selection bias in meta-analyses of gene-disease associations. PLoS. Med. 2: e409.

Thaha M, Pranawa, Yogiantoro M, Sutjipto, et al. (2008). Association of endothelial nitric oxide synthase Glu298Asp polymorphism with end-stage renal disease. Clin. Nephrol. 70: 144-154.

Thomas GD, Zhang W and Victor RG (2001). Nitric oxide deficiency as a cause of clinical hypertension: promising new drug targets for refractory hypertension. JAMA 285: 2055-2057.

Tobias A (1999). Assessing the influence of a single study in the meta-analysis estimate. Stata Tech. Bull. 8: 15-17.

Trikalinos TA, Salanti G, Khoury MJ and Ioannidis JP (2006). Impact of violations and deviations in Hardy-Weinberg equilibrium on postulated gene-disease associations. Am. J. Epidemiol. 163: 300-309.

Tsukada T, Yokoyama K, Arai T, Takemoto F, et al. (1998). Evidence of association of the ecNOS gene polymorphism with plasma NO metabolite levels in humans. Biochem. Biophys. Res. Commun. 245: 190-193.

Wu XF and Huang QY (2009). The a/b polymorphism in the eNOS gene is associated with essential hypertension but not type 2 diabetes in hubei Han Chinese. Prog. Mod. Biomed. 9: 69-72.

Yuan H, Li QX, Ping YH and Liu GZ (2007). Polymorphisms of endothelial nitric oxide synthase NOS3 4a/b and HindIII restriction site of the Y-chromosome in essential hypertension. Chin. J. Lab. Med. 30: 392-394.

Zhao Q, Su SY, Chen SF, Li B, et al. (2006). Association study of the endothelial nitric oxide synthase gene polymorphisms with essential hypertension in northern Han Chinese. Chin Med. J. 119: 1065-1071.

Zhao XY, Guo X, Qiu CC, Zhang DH, et al. (2005). Relationship of endothelial nitric oxide synthase gene polymorphism, the 27-bp repeat in intron 4 with essential hypertension of the northern Han nationality in China. Chin. J. Rehabil. Theory Pract. 11: 422-424.

Zintzaras E and Ioannidis JP (2005). Heterogeneity testing in meta-analysis of genome searches. Genet. Epidemiol. 28: 123-137.

Zintzaras E and Lau J (2008). Synthesis of genetic association studies for pertinent gene-disease associations requires appropriate methodological and statistical approaches. J. Clin. Epidemiol. 61: 634-645.

Zintzaras E, Kitsios G and Stefanidis I (2006). Endothelial NO synthase gene polymorphisms and hypertension: a metaanalysis. Hypertension 48: 700-710. 